\title{
Frequencies of CCR5- $\Delta 32$, CCR2-64I and SDF1-3'A mutations in Human Immunodeficiency Virus (HIV) seropositive Subjects and seronegative Individuals from the State of Pará in Brazilian Amazonia
}

\author{
Fernanda Andreza de Pinho Lott Carvalhaes ${ }^{1}$, Greice Lemos Cardoso $^{1}$, Antonio Carlos Rosário Vallinoto ${ }^{2}$, \\ Luiz Fernando Machado ${ }^{2}$, Marluisa de Oliveira Guimarães Ishak ${ }^{2}$, Ricardo Ishak ${ }^{2}$ and João Farias Guerreiro ${ }^{1}$ \\ ${ }^{1}$ Universidade Federal do Pará, Centro de Ciências Biológicas, Departamento de Patologia, \\ Laboratório de Genética Médica e Humana, Belém, Pará, Brazil. \\ ${ }^{2}$ Universidade Federal do Pará, Centro de Ciências Biológicas, Departamento de Patologia, \\ Laboratório de Virologia, Belém, Pará, Brazil.
}

\begin{abstract}
The distribution of genetic polymorphisms of chemokine receptors CCR5- $\Delta 32, \mathrm{CCR} 2-64$ I and chemokine (SDF1-3'A) mutations were studied in 110 Human Immunodeficiency Virus type 1 (HIV-1) seropositive individuals (seropositive group) and 139 seronegative individuals (seronegative group) from the population of the northern Brazilian city of Belém which is the capital of the state of Pará in the Brazilian Amazon. The CCR5- $\Delta 32$ mutation was found in the two groups at similar frequencies, i.e. $2.2 \%$ for the seronegative group and $2.7 \%$ for the seropositive group. The frequencies of the SDF1-3'A mutation were $21.0 \%$ for the seronegative group and $15.4 \%$ for the seropositive group, and the CCR2-64I allele was found at frequencies of $12.5 \%$ for the seronegative group and $5.4 \%$ for the seropositive group. Genotype distributions were consistent with Hardy-Weinberg expectations in both groups, suggesting that none of the three mutations has a detectable selective effect. Difference in the allelic and genotypic frequencies was statistically significant for the CCR2 locus, the frequency in the seronegative group being twice that found in the seropositive group. This finding may indicate a protective effect of the CCR2-64I mutation in relation to HIV transmission. However, considering that the CCR2-64I mutation has been more strongly associated with a decreased risk for progression for AIDS than to the resistance to the HIV infection, this could reflect an aspect of population structure or a Type I error.
\end{abstract}

Key words: CCR5, CCR2, SDF-1, HIV-1 infection, allele frequency, Brazilian Amazon.

Received: July 8, 2004; Accepted: April 5, 2005.

Several relatively recent studies (Kinter et al., 2000; Berger et al., 1999; O'Brien et al., 2000; Dragic et al., 1996; Barroga et al., 2000) have identified effects of genetic polymorphisms of the chemokine receptors on individual susceptibility to Human Immunodeficiency Virus type 1 (HIV-1) infection and the rate of progression to AIDS or death. The CCR5- $\triangle 32$ mutation results from a 32-basepair (bp) deletion from the coding region of the CCR5 gene that creates a premature stop codon, producing a defective receptor that is not expressed at the cell surface. Homozygotes resistant to R5-HIV-1 infection (the principal infecting HIV-1 strain) lack the requisite HIV-1 entry coreceptor CCR5 on their lymphoid cells (Dean et al.,

Send correspodence to João Farias Guerreiro. Universidade Federal do Pará, Centro de Ciências Biológicas, Departamento de Patologia, Laboratório de Genética Médica e Humana, 66075-900 Belém, Pará, Brazil. E-mail: joaofg@ufpa.br.
1996; O'Brien and Moore, 2000). Heterozygotes express less than half the wild-type levels of CCR 5 receptors, slowing HIV-1 replication, spread and pathogenesis (Wu et al., 1997; Benkirane et al., 1997). The CCR5- 432 allele is found at high frequencies (12\% to $15 \%$ ) in northern European populations, decreasing gradually from north to south (Martinson et al., 1997). Outside Europe, the mutation is found in populations of European descent. In Brazilian urban populations (HIV serological status not determined) the CCR5 variant has been found with frequencies between 0.030 and 0.065 (Passos and Picanço, 1998; Pereira et al., 2000; Munerato et al., 2003; Carvalhaes et al., 2004). This mutation is rare in Afro-Brazilians communities (0.008) and absent in Brazilian Amerindians (Leboute et al., 1999; Su et al., 2000; Grimaldi et al., 2002; Carvalhaes et al., 2004). Smith et al. (1997) states that CCR2-64I is a G to A substitution that results in the replacement of valine with 
isoleucine at position 64 of the CCR2 protein. Mellado et al. (1999) indicated that the CCR2-64I protein can preferentially dimerize with CXCR4 polypeptides (the HIV-1 receptor that replaces CCR5 as an entry receptor at later stages), whereas the wild-type CCR2 peptides do not. Thus, this mechanism suggests that CCR2-64I delays AIDS by limiting the transition from CCR5 to CXCR4 in infected individuals, a turning point in the collapse of the CD4-T lymphocyte cell population and a prelude to AIDS-defining disease (Berger et al., 1999). The CCR2-64I allele has been found at relatively high average frequencies in almost all populations studied to date, i.e.: European, 13\%; African, 17\%, Asian 13\% (Su et al., 1999, 2000; Martinson et al., 2000. A previous study performed on a sample of the general population of the northern Brazilian city of Belém, the capital of the state of Pará, population around 1,4 million (Brazilian Institute of Geography and Statistics - IBGE, 2004) in the Brazilian Amazon revealed the presence of the CCR2-64I mutation at a frequency of 0.161 (Carvalhaes et al., 2004) but higher frequencies have been found in Afro-Brazilians (0.230), whereas in Brazilian Amerindians the frequency of this mutation varies from 0.030 to 0.300 (Su et al, 1999; Acosta et al., 2003; Carvalhaes et al., 2004).

Stromal-derived factor-1 (SDF-1) is the chemokine ligand of CXCR4, the coreceptor used by the more pathogenic X4HIV-1 strains for cell entry (Lu et al., 1997; Björndal et al., 1997; Wang et al., 2003). A G-to-A substitution at position 801 in the 3' untranslated region (UTR) of the SDF-1 gene (SDF1-3'A allele) has been reported to slow disease progression (Winkler et al., 1998; Dezzutti et al., 2000), although this finding is still controversial (Ioannidis et al., 2001). Although allele-specific cellular or virological differences have not been explicitly established, the delay in onset of AIDS observed in SDF1-3'A homozygotes might result from overproduction of SDF1 in certain tissue compartments, postponing the CCR5-CXCR4 transition. A synergistic protective effect in individuals carrying SDF1-3'A and CCR2-64I would be consistent with this model. The SDF1-3'A allele is widely distributed, and has particularly high frequencies in Oceania, especially in New Guinean Highlanders (up to $72 \%$ ), but is less common (3\% to $12 \%$ ) in African populations and has been found with frequencies between 15\% and 22\% in Europeans (Su et al., 1999, 2000). In urban Brazilian populations not tested for HIV infection the SDF1-3'A allele was found at frequency of 0.223 in the population of Belém (Carvalhaes et al. 2004). In non-urban populations this variant was found at frequency of 0.153 in Afro-Brazilian communities and at frequencies of 0.060 to 0.227 in Amerindian tribes from the Brazilian Amazon (Su et al., 1999; Carvalhaes et al. 2004).

The current article describes the frequency of the CCR5-A32, CCR2-64I and SDF1-3'A mutations in 110 HIV-1 seropositive individuals and 139 seronegative individuals from Belém. The survey was carried out to investi- gate the possible influence of these genetic mutations on HIV transmission in the population of Belém.

Blood samples were randomly and anonymously collected from 249 individuals from Belém, all samples being collected with the informed consent of the participants. The HIV-1 seronegative individuals consisted of 20 females and 119 males (seronegative group, $\mathrm{n}=139$; age range: 17-49 years) who were blood donors at the Hemotherapy and Hematology Center of the state of Pará in Belém. The HIV-1 seropositive individuals consisted of 35 females and 75 males (seropositive group, $\mathrm{n}=110$; age range: $23-82$ years) who attended the Reference Unit for Special Infectious and Parasitic Diseases (URE-DIPE) in Belém between 1998 and 2002. The mode of HIV-1 transmission was clear for only 74 of the seropositive individuals (71 having been infected by sexual transmission and 03 by transfusion of HIV-1-contaminated blood or by sharing contaminated syringes and needles), the remaining 36 seropositive individuals being unable to identify the mode of HIV-1 transmission.

The CCR $5 \Delta 32$ genotype was determined by PCR with primers spanning the $32 \mathrm{bp}$ deletion (Martinson et al., 1997). The SDF1-3'A and CCR2-64I mutations were detected by PCR with primers covering polymorphic sites, followed by $M s p \mathrm{I}$ and $B s a \mathrm{BI}$ digestion, respectively, and restriction fragment length polymorphism (RFLP) analysis as described by Voevodin et al. (1999).

Allele frequencies and expected Hardy-Weinberg values were estimated by the maximum likelihood method using the TFPGA program version 3.1 (Miller, 1998). Statistical comparisons of allele and genotype frequencies between samples used the chi-squared $\left(\chi^{2}\right)$ test function of the same program.

Genotype and allele frequency distributions recorded for the three loci are presented in Table 1. Genotype distributions were consistent with the Hardy-Weinberg expectations for the three loci in both groups. Allele frequencies of the CCR5 locus were similar in both groups, being $2.2 \%$ in the seronegative group and $2.7 \%$ in the seropositive group $(\mathrm{p}=0.771)$. The SDF1-3'A mutation was common in both groups but relatively more so $(21 \%)$ in the seronegative group as compared to seropositive group (15.4\%), although this difference was not significant at $p=0.134$. The CCR2-64I allele was also relatively common but its frequency in the seropositive group was $5.4 \%$ and hence less than half of the $12.5 \%$ found in the seronegative group, this difference being statistically significant at $\mathrm{p}=0.0135$.

The fact that genotype distributions of all three loci are in Hardy-Weinberg equilibrium in both groups suggests that none of the mutations studied here has a detectable selective effect, as observed previously in other human populations. This is supported by the lack of statistically significant differences between seropositive and seronegative groups in the allele and genotype frequencies at the CCR5 ( $p=0.771)$ and SDF-1 $(p=0.134)$ loci. By con- 
Table 1 - Allele and genotype frequencies of the CCR5, CCR2 and SDF-1 loci in Human immunodeficiency virus (HIV) seropositive and seronegative individuals from Belém.

\begin{tabular}{|c|c|c|c|c|c|c|}
\hline \multirow[t]{2}{*}{ Locus/group } & \multirow[t]{2}{*}{$\mathrm{N}$} & \multicolumn{3}{|c|}{ Genotype frequency } & \multirow{2}{*}{$\frac{\text { Allele frequency }}{\Delta 32}$} & \multirow{2}{*}{$\begin{array}{c}\text { Expected Hardy-Weinberg } \\
\text { p-value }\end{array}$} \\
\hline & & wt/wt & $\mathrm{wt} / \Delta 32$ & $\Delta 32 / \Delta 32$ & & \\
\hline \multicolumn{7}{|l|}{ CCR5D32 } \\
\hline Seronegative & 139 & 133 & 6 & 0 & 0.022 & 0.7948 \\
\hline Seropositive & 110 & 104 & 6 & 0 & 0.027 & 0.7534 \\
\hline CCR2-64I & & wt/wt & $\mathrm{wt} / 64 \mathrm{I}$ & $64 \mathrm{I} / 64 \mathrm{I}$ & $64 \mathrm{I}$ & \\
\hline Seronegative & 112 & 84 & 28 & 0 & 0.125 & 0.1306 \\
\hline Seropositive & 110 & 98 & 12 & 0 & 0.054 & 0.4870 \\
\hline SDF1-3'A & & wt/wt & wt/3'A & 3'A/3'A & 3'A & \\
\hline Seronegative & 126 & 96 & 32 & 3 & 0.210 & 0.7584 \\
\hline Seropositive & 110 & 79 & 28 & 3 & 0.154 & 0.8633 \\
\hline
\end{tabular}

trast, the frequency of the CCR2-64I allele in the HIV-1 seropositive group was significantly lower $(p=0.014)$ than that of the seronegative group. In the case of the CCR5 locus, the low frequency of the CCR5- $\triangle 32$ mutation implies that the protective genotype may be too rare for confirmation. The absence of significant differences in the allelic and genotypic frequencies between HIV-1 seropositive and seronegative individuals has also been reported in other Brazilian populations. Grimaldi et al. (2002) reported such a lack of difference for the population of Salvador, the capital of the Brazilian state of Bahia, total population estimated at 2,631,831 (IBGE, 2004) and Munerato et al. (2003) in the population of Brazilian city of São Paulo, the largest Brazilian city with a population of about 11 million (IBGE, 2004).

Our results for the SDF-1 locus are consistent with findings in other human groups, which have shown that the SDF1-3'A mutation has no effect on HIV transmission, but is related to the delay in onset of AIDS. In fact, homozygosity for the SDF1-3'A allele has been reported to slow disease progression, but results obtained in an international meta-analysis of individual patient data showed that SDF1-3'A homozygosity gave no such protection (Ioannidis et al., 2001). With regard to the CCR2 locus, the CCR2-64I allele has been found at relatively high average frequencies in European, African and Brazilian Amerin-

Table 2 - Allele and genotype frequencies of CCR5, CCR2 and SDF-1 loci in Human Immunodeficiency Virus (HIV) seropositive and seronegative Brazilians.

\begin{tabular}{|c|c|c|c|c|c|c|}
\hline \multirow[t]{2}{*}{ Locus/group/place } & \multirow[t]{2}{*}{$\mathrm{N}$} & \multicolumn{3}{|c|}{ Genotype frequency } & \multirow{2}{*}{$\begin{array}{c}\text { Allele frequency } \\
\Delta 32\end{array}$} & \multirow[t]{2}{*}{ Reference } \\
\hline & & wt/wt & $\mathrm{wt} / \Delta 32$ & $\Delta 32 / \Delta 32$ & & \\
\hline \multicolumn{7}{|l|}{ CCR5 } \\
\hline \multicolumn{7}{|l|}{ Seronegative } \\
\hline Southeast Brazil & 229 & 205 & 24 & 0 & 0.052 & Pereira et al. (2000) \\
\hline Joinville (SC) & 99 & 87 & 11 & 1 & 0.065 & Grimaldi et al. (2002) \\
\hline Salvador (BA) & 549 & 520 & 29 & 0 & 0.026 & Grimaldi et al. (2002) \\
\hline \multicolumn{7}{|l|}{ Seropositive } \\
\hline São Paulo (SP) & 183 & 162 & 21 & 0 & 0.057 & Munerato et al. (2003) \\
\hline Salvador (BA) & 113 & 103 & 10 & 0 & 0.044 & Grimaldi et al. 2002) \\
\hline CCR2 & & $\mathrm{wt} / \mathrm{wt}$ & wt/64I & $64 \mathrm{I} / 64 \mathrm{I}$ & $64 \mathrm{I}$ & \\
\hline \multicolumn{7}{|l|}{ Seronegative } \\
\hline Salvador (BA) & 305 & 227 & 73 & 5 & 0.140 & Acosta et al. (2003) \\
\hline Joinville (SC) & 89 & 57 & 32 & 0 & 0.180 & Acosta et al. (2003) \\
\hline \multicolumn{7}{|l|}{ Seropositive } \\
\hline São Paulo (SP) & 178 & 150 & 27 & 1 & 0.082 & Munerato et al. (2003) \\
\hline SDF & & $\mathrm{wt} / \mathrm{wt}$ & $w t / 3 ’ A$ & $3^{\prime} \mathrm{A} / 3^{\prime} \mathrm{A}$ & 3'A & \\
\hline \multicolumn{7}{|l|}{ Seropositive } \\
\hline São Paulo (SP) & 62 & 41 & 21 & 0 & 0.169 & Watanabe et al. (2003) \\
\hline
\end{tabular}

Key: $\mathrm{SC}=$ Santa Catarina State; $\mathrm{BA}=$ Bahia state; $\mathrm{SP}=$ São Paulo state. 
dian populations, which indicates that the expected frequencies of individuals who would be wholly or partially resistant to the infection are usually high, with consequent lower rates of disease transmission. However, considering that the CCR2-64I is more strongly associated with a decreased risk for progression to AIDS than to resistance to the HIV infection, the suggested protective effect of this variant on HIV transmission in the population of Belém may simply reflect an aspect of the population structure of this city or to be due to a Type I error (i.e. the probability of falsely rejecting the hypothesis that two samples are not different in a series of comparisons). The distribution of the CCR2-64I and SDF1-3'A mutations in seropositive and seronegative individuals from Belém were not different from those of other Brazilian populations in São Paulo and Bahia (Table 2), although comparisons of allelic and genotypic frequencies among seropositive subjects and uninfected healthy individuals in these studies are not available.

\section{Acknowledgments}

This study was funded by the Pará State Fund for Science and Technology (FUNTEC), of the State Executive Secretariat for Science, Technology and the Environment and the Federal University of Pará.

\section{References}

Acosta AX, Grimaldi R, Shindo N, Spínola JL and Galvão-Castro B (2003) Distribution of the CCR2-64I allele in three Brazilian ethnic groups Genet Mol Biol 26:241-243.

Barroga CF, Raskino C, Fangon MC, Palumbo PE, Baker CJ, Englund JA and Spector SA (2000) The CCR5 332 allele slows disease progression of human immunodeficiency virus 1-infected children receiving antiretroviral treatment. J Infect Dis 182:413-419.

Benkirane M, Jin DY, Chun RF, Koup RA and Jeang KT (1997) Mechanism of transdominant inhibition of CCR5-mediated HIV-1 infection by ccr5 $\Delta 32$. J Biol Chem 272:3060330606.

Berger EA, Murphy PM and Farber JM (1999) Chemokine receptors as HIV-1 coreceptors: Roles in viral entry, tropism, and disease. Annu Rev Immunol 17:657-700.

Björndal A, Deng H, Jansson M, Fiore JR, Colognesi C, Karlsson A, Albert J, Scarlatti G, Littman DR and Fenyo EM (1997) Coreceptor usage of primary human immunodeficiency virus type I isolates varies according to biological phenotype. J Virol 71:7478-7487.

Brazilian Institute for Geography and Statistic (IBGE), http://www.ibge.gov.br.

Carvalhaes FAPL, Cardoso GL, Hamoy IG, Liu YT and Guerreiro JF (2004). Distribution of CCR5- $\Delta 32$, CCR2-64I, and SDF1-3'A mutations in populations from Brazilian Amazon region. Hum Biol 76:90-93.

Dean M, Carrington M, Winkler C, Huttley GA, Smith MW, Allikmets R, Goedert JJ, Buchbinder SP, Vittinghoff E, Gomperts E, Donfield S, Vlahov D, Kaslow R, Saah A, Rinaldo C, Detels R and, O’Brien SJ (1996) Genetic restric- tion of HIV-1 infection and progression to AIDS by a deletion allele of the CKR5 structural gene. Science 273:18561862.

Dezzutti CS, Guenthner PC, Green TA, Cohen OJ, Spira TJ and Lal RB (2000) Stromal-derived factor-1 chemokine gene variant is associated with the delay of HIV-1 disease progression in two longitudinal cohorts. AIDS 14:894-496.

Dragic T, Litwin V, Allaway GP, Martin SR, Huang Y, Nagashima KA, Cayanan C, Maddon PJ, Koup RA, Moore JP and Paxton WA (1996) HIV-1 entry into CD4+ cells is mediated by the chemokine receptor CC-CKR-5. Nature 381:667673.

Grimaldi R, Shindo N, Acosta AX, Dourado I, Brites C, de Melo Carvalho O, Brito I, Bou-Habib DC and Galvao-Castro B (2002) Prevalence of the CCR5 $\Delta 32$ mutation in Brazilian populations and cell susceptibility to HIV-1 infection. Hum Genet 111:102-4.

Ioannidis JP, Rosenberg PS, Goedert JJ, Ashton LJ, Benfield TL, Buchbinder SP, Coutinho RA, Eugen-Olsen J, Gallart T, Katzenstein TL, Kostrikis LG, Kuipers H, Louie LG, Mallal SA, Margolick JB, Martinez OP, Meyer L, Michael NL, Operskalski E, Pantaleo G, Rizzardi GP, Schuitemaker H, Sheppard HW, Stewart GJ, Theodorou ID, Ullum H, Vicenzi E, Vlahov D, Wilkinson D, Workman C, Zagury JF and O'Brien TR (2001) Effects of CCR5- $\Delta 32$, CCR2-64I, and SDF-1 3'A alleles on HIV-1 disease progression: An international meta-analysis of individual-patient data. International meta-analysis of HIV host genetics. Ann Intern Med 135:782-795

Kinter A, Arthos J, Cicala C and Fauci AS (2000) Chemokines, cytokines and HIV: A complex network of interactions that influence HIV pathogenesis. Immunol Rev 177:88-98.

Leboute APM, Carvalho MWP and Simões AL (1999) Absence of the $\Delta$ ccr5 mutation in indigenous populations of the Brazilian Amazon. Hum Genet 105:442-443.

Lu Z, Berson JF, Chen Y, Turner JD, Zhang T, Sharron M, Jenks MH, Wang Z, Kim J, Rucker J, Hoxie JA, Peiper SC and Doms RW (1997) Evolution of HVI-1 coreceptor usage through with distinct CCR5 and CXCR4 domains. Proc Natl Acad Sci USA 94:6426-31.

Martinson JJ, Chapman NH, Rees DC, Liu YT and Clegg JB (1997) Global distribution of the CCR5 gene 32-base pair deletion. Nature Genet 16:100-103.

Martinson JJ, Hong L, Karanicolas R, Moore JP and Kostrikis LG (2000) Global distribution of the CCR2-64I/CCR5-59653T HIV-1 disease-protective haplotype. AIDS 14:483-489.

Mellado M, Rodriguez-Frade JM, Vila-Coro AJ, de Ana AM and Martinez-AC (1999) Chemokine control of HIV-1 infection. Nature 400:723-724.

Miller MP (1998) Tools for Population Genetic Analysis (TFPGA) version 1.3. Department of Biological Sciences, Northern Arizona University, Box 5640 http://herb.bio.nau.ed/ miller.

Munerato P, Azevedo ML, Sucupira MC, Pardini R, Pinto GH, Catroxo M, Souza IE and Diaz RS. (2003) Frequency of polymorphisms of genes coding for HIV-1 co-receptors CCR5 and CCR2 in a Brazilian population. Braz J Infect Dis 4:236-240.

O'Brien SJ and Moore JP (2000) The effect of genetic variation in chemokines and their receptors on HIV transmission and progression to AIDS. Immunol Rev 177:99-111. 
O'Brien SJ, Nelson GW, Winkler CA and Smith MW (2000) Polygenic and multifactorial disease gene association in man: Lessons from AIDS. Annu Rev Genet 34:563-591.

Passos GA Jr and Picanço VP (1998) Frequency of the delta ccr5 deletion allele in the urban Brazilian population. Immunol Lett 61:205-207.

Pereira RW, Pires ER, Duarte APM, Moura RP, Monteiro E, Torloni H, Proietti AB, Simpson AJG and Pena SDJ (2000) Frequency of the CCR5 32 allele in Brazilians: A study in colorectal cancer and in HTLV-I infection. Genet Mol Biol 23:523-526.

Smith MW, Dean M, Carrington M, Winkler C, Huttley GA, Lomb DA, Goedert JJ, O’Brien TR, Jacobson LP, Kaslow R, Buchbinder S, Vittinghoff E, Vlahov D, Hoots $\mathrm{K}$ and Hilgartner MW (1997) Contrasting genetic influence of CCR2 and CCR5 variants on HIV-1 infection and disease progression. Science 277:959-965.

Su B, Jin L, Hu F, Xiao J, Luo J, Lu D, Zhang W, Chu J, Du R, Geng Z, Qiu X, Xue J, Tan J, O’Brien SJ and Chakraborty R (1999) Distribution of two HIV-1-resistant polymorphisms (SDF1-3'A and CCR2-64I) in East Asian and world populations and its implication in AIDS epidemiology. Am J Hum Genet 65:1047-1053.

Su B, Sun G, Lu D, Xiao J, Hu F, Chakraborty R, Deka R and Jin L (2000) Distribution of three HIV-1 resistance-conferring polymorphisms (SDF1-3'A, CCR2-64I, and CCR5-delta32) in global populations. Eur J Hum Genet 8:975-979.
Voevodin A, Samilchuk E and Dashti S (1999) Frequencies of SDF-1 chemokine, CCR-5, and CCR-2 chemokine receptors gene alleles conferring resistance to human immunodeficiency virus type 1 and AIDS in Kuwaitis. J Med Virol 58:54-58.

Wang FS, Hong WG, Cao Y, Liu MX, Jin L, Hu LP, Wang Z, Feng TJ, Hou J, Zhang B, Shi M, Xu DP, Lei ZY, Wang B, Liu ZD, Ye JJ, Peng L, Qiu Y and Winkler C (2003) Population survey of CCR5 $\triangle 32$, CCR5m303, CCR2b64I and SDF1-3'A allele frequencies in indigenous Chinese healthy individuals, and in HIV-1-infected and HIV-1-uninfected individuals in HIV-1 risk groups. J Acquir Immune Defic Syndr 32:124-130.

Watanabe MA, de Oliveira Cavassin GG, Orellana MD, Milanezi CM, Voltarelli JC, Kashima S and Covas DT (2003) SDF-1 gene polymorphisms and syncytia induction in Brazilian HIV-1 infected individuals. Microb Pathog 35:31-34.

Winkler C, Modi W, Smith MW, Nelson GW, Wu X, Carrington M, Dean M, Honjo T, Tashiro K, Yabe D, Buchbinder S, Vittinghoff E, Goedert JJ, O'Brien TR, Jacobson LP, Detels R, Donfield S, Willoughby A, Gomperts E, Vlahov D, Phair J and O'Brien SJ (1998) Genetic restriction of AIDS pathogenesis by an SDF-1 chemokine gene variant. Science 279:389-393.

Wu L, Paxton WA, Kassam N, Ruffing N, Rottman JB, Sullivan N, Choe H, Sodroski J, Newman W, Koup RA and Mackay CR (1997) CCR5 levels and expression, pattern correlate with infectability by macrophage-tropic HIV-1, in vitro. J Exp Med 185:1681-1691.

Associate Editor: Francisco Mauro Salzano 